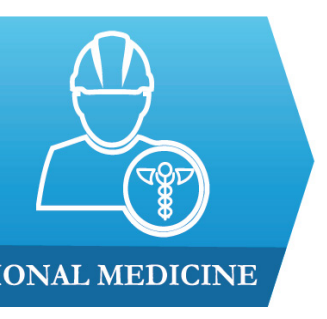

1) First Department, Dental Medicine School, Victor Babeș University of Medicine and Pharmacy Timișoara, Romania

2) Fifth Department - Internal Medicine, Victor Babeș University of Medicine and Pharmacy Timișoara, Romania

3) Mechatronics Department, Polytechnic University of Timişoara, Romania

\title{
The use of baropodometric analysis in musculoskeletal disorders of dentists working in orthostatic posture - a series of 3 cases
}

\author{
Mioara Raluca Cosoroabă ${ }^{1}$, Liviu Cirin ${ }^{2}$, Andrei Zoltan Farkas³ \\ Veronica Argeșanu ${ }^{3}$, Ioana Cristina Talpos-Niculescu', \\ Mirella Dorina Anghel ${ }^{1}$, Mihai Romînu ${ }^{1}$, Meda-Lavinia Negrutiu ${ }^{1}$
}

\begin{abstract}
Introduction. Musculoskeletal disorders (MSDs) caused by incorrect working posture among dentists is a serious issue and one that leads to decreased productivity and quality of life.

Aim. The aim of this study was to evaluate the impact of MSDs caused by postural errors in dental healthcare professionals on the body's center of gravity through a new and innovative technique - baropodometry.

Methods. In this study we included 3 oral healthcare specialists with over 20 years experience of practicing in orthostatism, with confirmed work-related MSDs, and performed a baropodometric analysis on them.

Results. According to the analysis, all 3 test subjects had alterations of the body's center of gravity, with uneven distribution of pressures on the feet being recorded by the baropodometer.

Conclusion. In an effort to maintain a good field of view and workplace in orthostatism, the subject is forced to adopt an non-ergonomic position that leads to uneven weight distribution, shifted center of gravity that eventually cause musculoskeletal disorders.
\end{abstract}

Keywords: dentistry, musculoskeletal disorders, ergonomics, baropodometry, posture

\section{Introduction}

Human bipedalism evolved approximately 4 million years ago and is considered to be the most energy efficient way of walking, being almost $75 \%$ less energetically costly than quadrupedal walking. The human bipedal posture and locomotion has led to certain musculoskeletal adaptations in the human body, the most important ones regarding the vertebral spine and feet. However, long term orthostatism can cause a variety of musculoskeletal disorders (MSD), such as chronic low back pain (LBP) and many others. This is an issue especially in the context of prolonged orthostatic posture, such as in the workplace, as disorders like LBP are widely associated with a lower quality of life $[1,2,3,4,5]$.
Dentists are a category of healthcare professionals especially at risk of MSDs due to the nature of their work, involving repetitive motions, prolonged static postures, excessive exertion of small muscles, tight grip of instruments and raised arms position. The most common complaints from dentists are neck and back pain, with LBP being the most frequent and a major cause of work absences $[4,5,6,7]$.

Even though the ISO 11226 Ergonomic-Evaluation of static working postures standard, published in 2000 encourages a seated working position, a large number of dentists still prefer working in orthostatism (Figure 1), years of habit preventing them from switching positions [8]. 


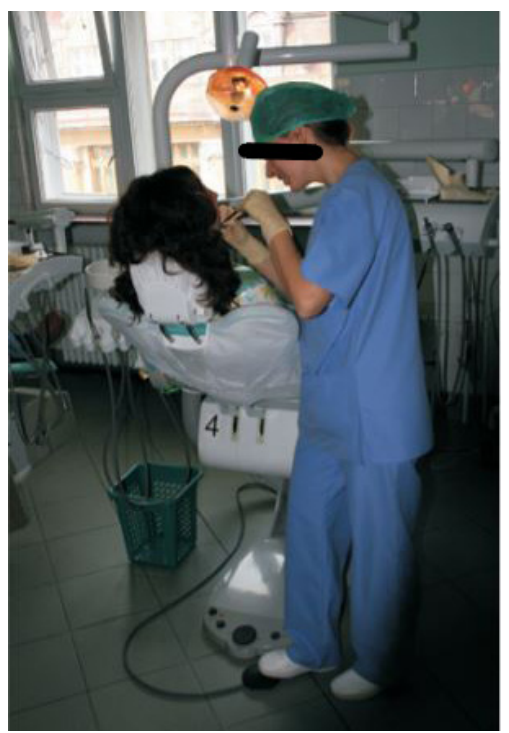

Figure 1. Orthostatic posture.

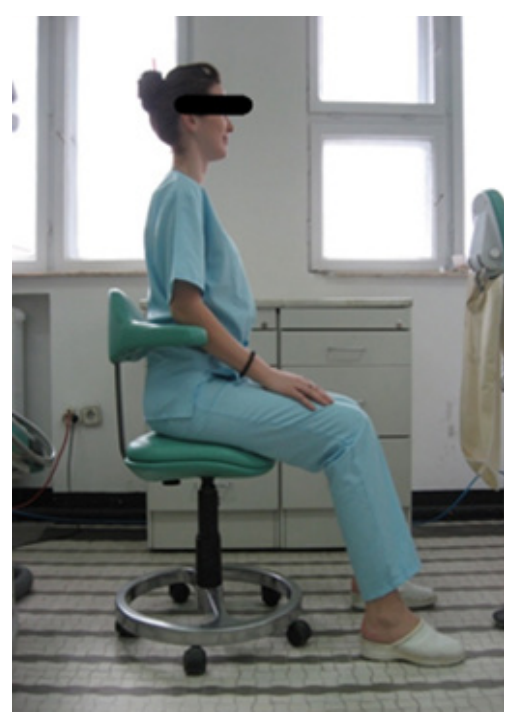

Figure 2. Seated position (recommended by the ISO 11226 standard).

\section{Aim}

The objective of this study was to evaluate the impact of MSDs caused by postural errors in dental healthcare professionals on the body's center of gravity through a new and innovative technique - baropodometry $[9,10]$.

\section{Methods}

The study was performed on 3 dentists, two women and one man (Table I), each with over 20 years work experience in orthostatism and presenting musculoskeletal symptoms that could be attributed to postural syndrome - a condition whereby prolonged or repetitive poor positioning of the body leads to pain and dysfunction. Symptoms included in the umbrella term "postural syndrome" were ache or pain of the locomotor system during activities that place sustained stress on otherwise normal tissue (no trauma present on the respective joint or muscle) and is most commonly caused by long-term poor posture (Figure 3).

All subjects complained of neck, shoulder and lower back pain, symptoms which appeared after they started practicing dentistry. All subjects included in this study signed an informed consent form before entering the study.

Table I. Study group demographics.

\begin{tabular}{|l|c|c|c|c|c|} 
& Gender & $\begin{array}{c}\text { Age } \\
(\text { years })\end{array}$ & $\begin{array}{c}\text { Height } \\
(\mathbf{m})\end{array}$ & $\begin{array}{c}\text { Weight } \\
(\mathbf{k g})\end{array}$ & $\begin{array}{c}\text { BMI } \\
\left(\mathbf{k g} / \mathbf{m}^{2}\right)\end{array}$ \\
\hline Subject 1 & male & 53 & 1.68 & 74 & 26.2 \\
Subject 2 & female & 58 & 1.64 & 49 & 18.2 \\
Subject 3 & female & 51 & 1.57 & 53 & 21.5
\end{tabular}

We photographed their posture while working, performed x-rays of lumbar (Table II) and cervical spine (Table III) and used a baropodometer as a tool to evaluate postural deviations caused by practicing in orthostatism.

Table II. Lumbar spine lateral X-ray results.

\begin{tabular}{l|l} 
& \multicolumn{1}{|c}{ Lumbar spine X-ray result } \\
Subject 1 & profile rectitude; anterior osteophytes L5 \\
lumbar dextroscoliosis (AP projection was also \\
Subject 2 & $\begin{array}{l}\text { performed); L3-L5 marginal anterior osteophytes; L3- } \\
\text { L5 disc space narrowing }\end{array}$ \\
Subject 3 & L4-S1 disc space narrowing
\end{tabular}

Table III. Cervical spine X-ray results.

\begin{tabular}{l|l} 
& \multicolumn{1}{c}{ Cervical spine X-ray results } \\
Subject 1 Multiple osteophytes; C6-C7 disc space narrowing \\
Subject $2 \begin{array}{l}\text { C4-C7 marginal anterior osteophytes and posterior C5- } \\
\text { C7; C5-C7 disc space narrowing; cervical rectitude }\end{array}$ \\
Subject $3 \begin{array}{l}\text { C2-C3 \& C5-C7 disc space narrowing; cervical } \\
\text { rectitude }\end{array}$
\end{tabular}

Having evaluated and diagnosed MSDs as a consequence of poor posture through symptomatology, photography of working position and medical imaging (Figure 4 and 5), we proceeded to assess postural deviations in subjects using baropodometry. Baropodometry is the study of static and dynamic foot pressures or plantar pressure using a foot pressure plate and is reported to be an excellent tool in posture research and evaluation [9]. Static postural analysis was performed with a baropodometer using the Milletrix software package, to objectify the severity of postural deviations caused by long-term practicing in this manner. Measurements were performed with the subjects barefoot. 


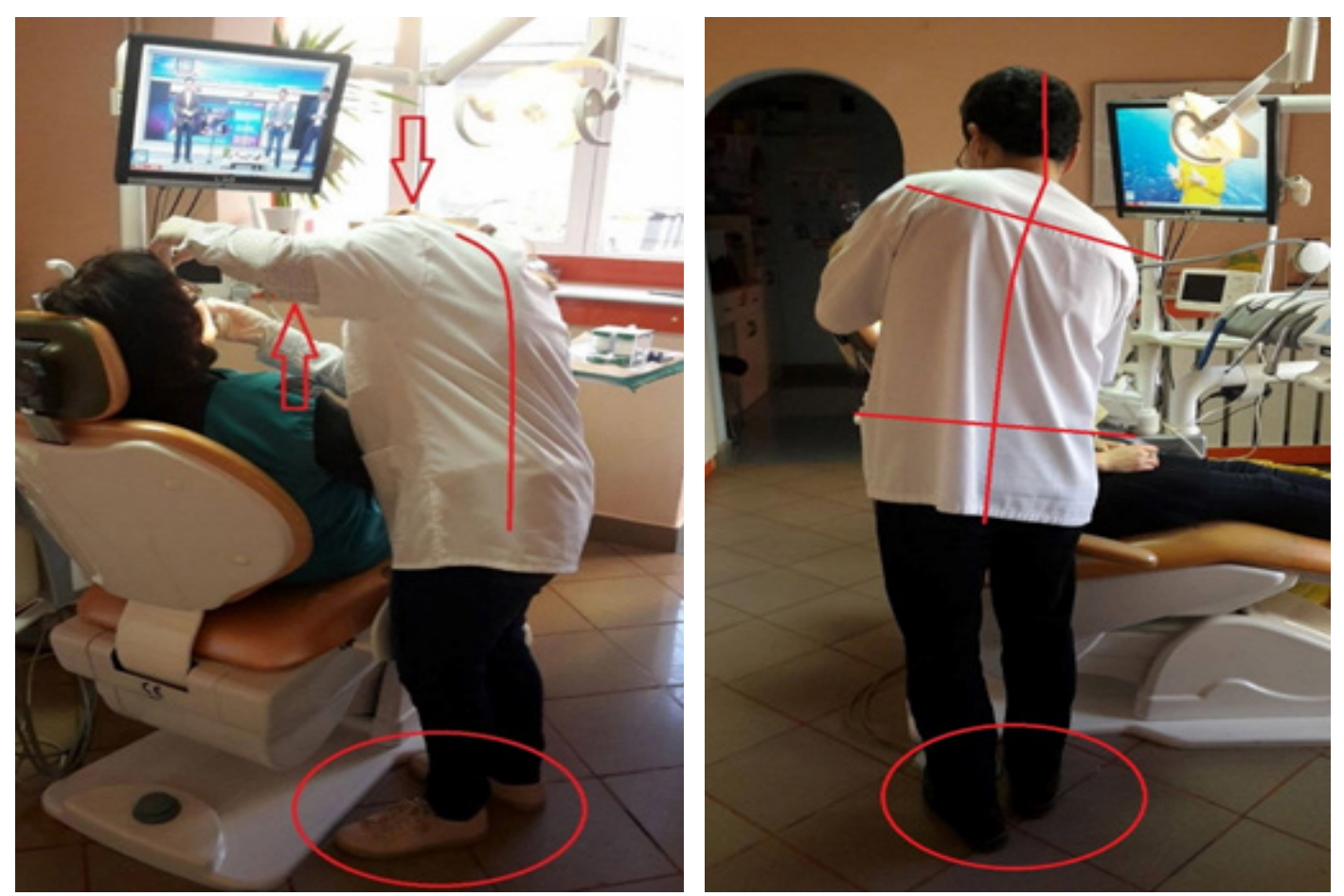

Figure 3. Examples of incorrect working posture among study subjects with markings being used to emphasize abnormal loads and strains on joints - consequences of trying to maintain a good field of view and workspace in orthostatism.
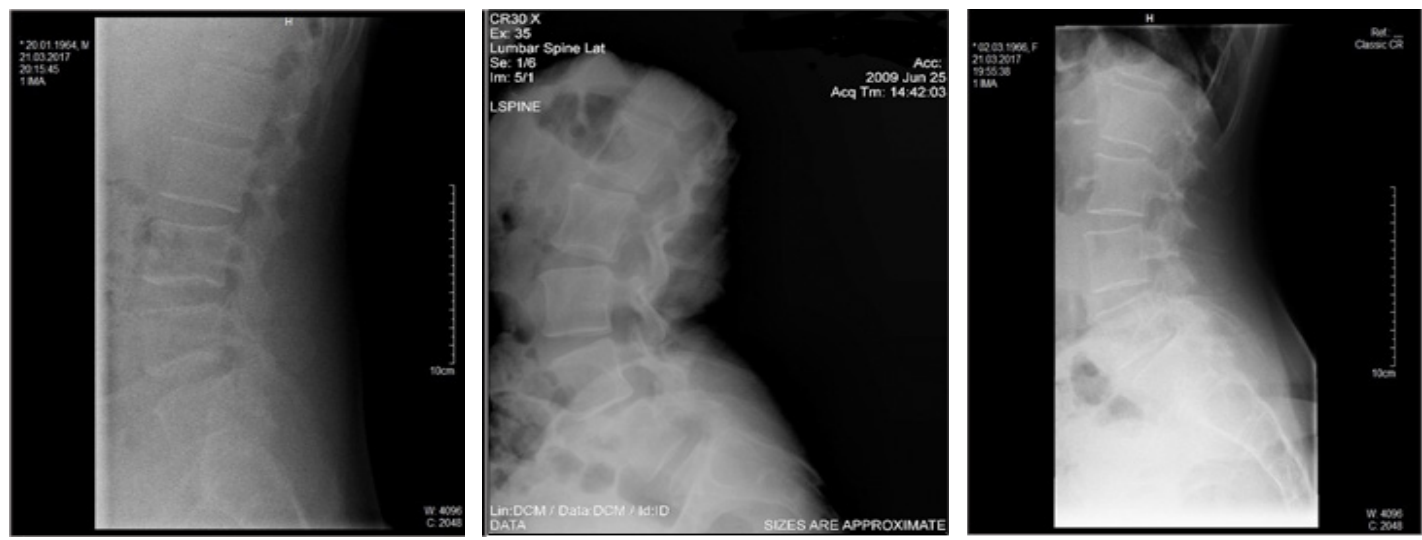

Figure 4. Lumbar spine X-rays of subjects (lateral projection); from left to right subject 1, $2 \& 3$.
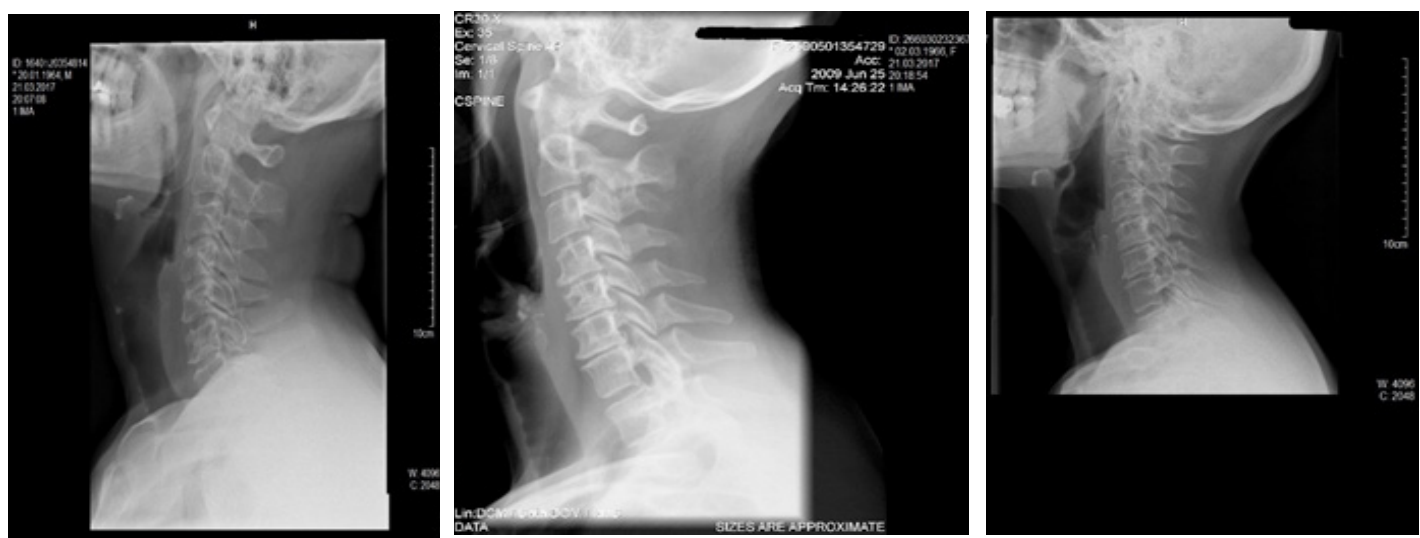

Figure 5. Cervical spine X-rays of subjects; from left to right subject 1, 2 \& 3 . 


\section{Results}
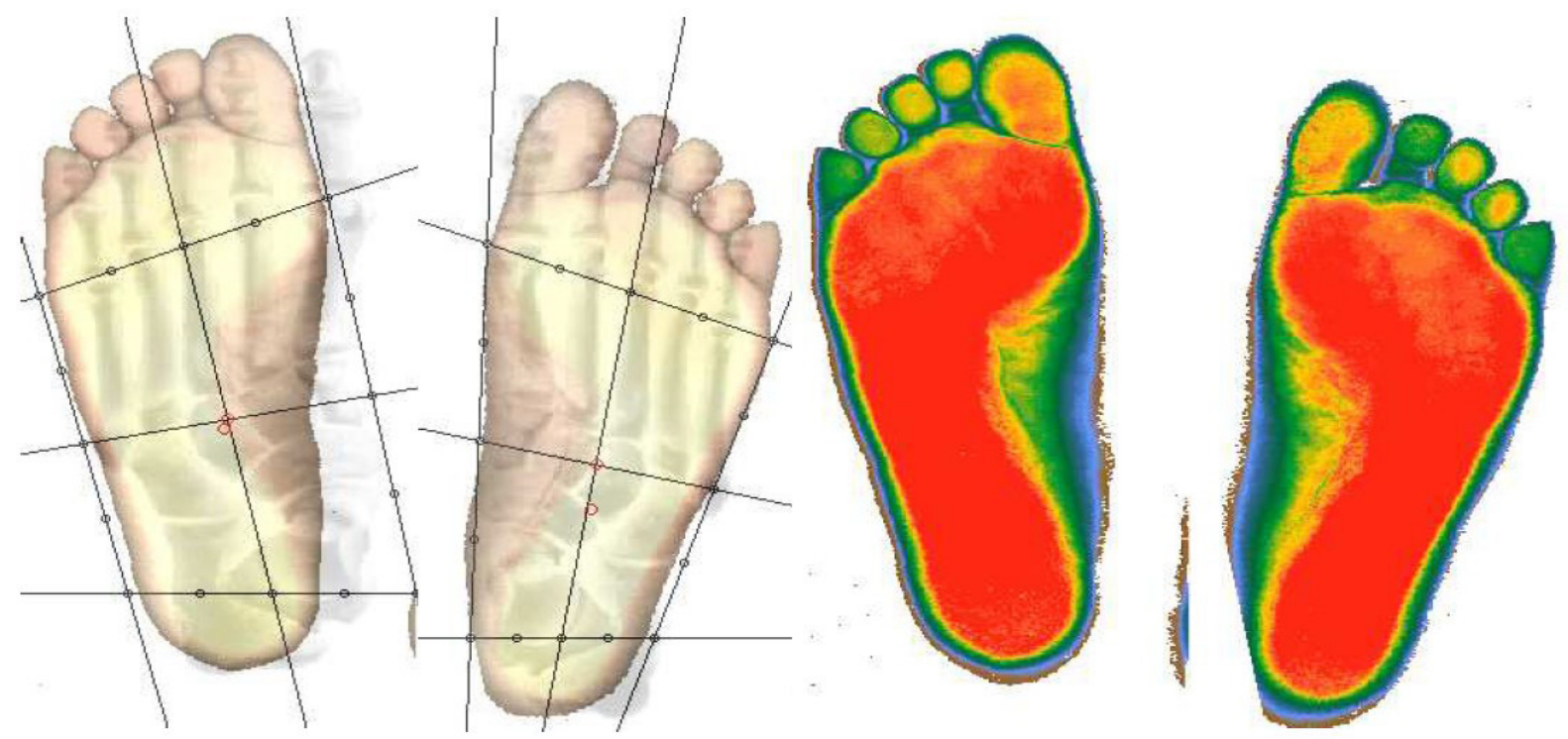

$\begin{array}{lrrrl} & \text { LF } & \text { RG } & & \\ \text { Foot Length } & 26.35 & 26.15 & \mathrm{~cm} & \text { Foot Angle } \\ \text { Metatarsal Width } & 11.21 & 11.06 & \mathrm{~cm} & \text { Divergence Angle } \\ \text { Midfoot Length } & 14.42 & 14.14 & \mathrm{~cm} & \text { Tarsal Epicenter } \\ \text { Heel Width } & 10.49 & 6.65 & \mathrm{~cm} & \text { Centroid (to end rearfoot) } \\ \text { Heel Length } & 7.29 & 7.19 & \mathrm{~cm} & \text { Subtalar Joint Med angle } \\ \text { Heel Perimeter } & 13.96 & 10.87 & \mathrm{~cm} & \text { Subtalar Joint Lat angle } \\ \text { Lateral width } & 7.19 & 7.66 & \mathrm{~cm} & \text { Left Foot } \\ \text { Shoe \#: } & 8.5 & 8 & & \end{array}$

Figure 6. Subject 1: Feet dimensions and characteristics.

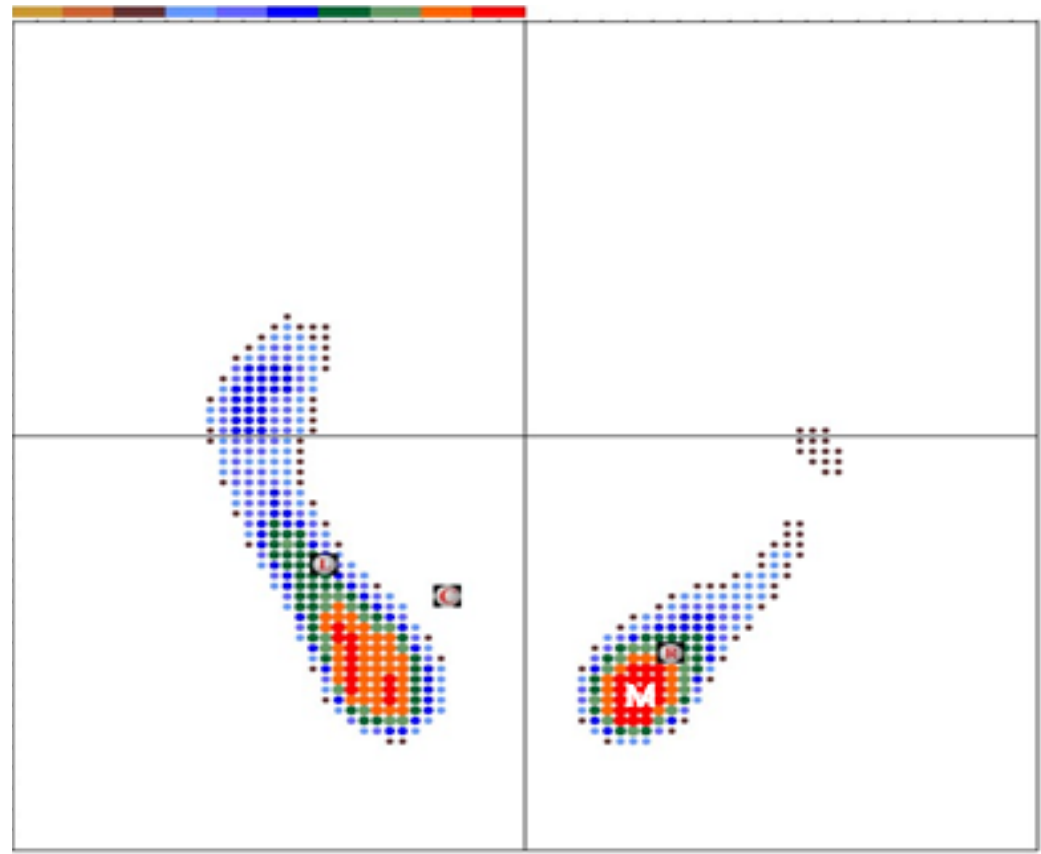

\begin{tabular}{|c|c|c|}
\hline $\begin{array}{l}\text { Surface }(\mathrm{cm}) \\
\text { P.Max }(\mathrm{g} / \mathrm{cm}) \\
\text { P.Avg }(\mathrm{g} / \mathrm{cm}) \\
\text { Feet angle ( ) } \\
\text { Cof }\langle\mathrm{L}-\mathrm{R}\rangle \text { angle }(9\end{array}$ & & $\begin{array}{l}128.75 \\
1095.5 \\
574.8 \\
52.1 \\
-17.6\end{array}$ \\
\hline Forefoot & Sx & $\mathrm{Dx}$ \\
\hline $\begin{array}{l}\text { Surface }(\mathrm{cm},) \\
\text { Load }(\mathrm{Kg}) \\
\text { Weight ratio <R F> }\end{array}$ & $\begin{array}{l}21.75 \\
13.2 \\
20.5 \%\end{array}$ & $\begin{array}{l}0.75 \\
0.3 \\
0.8 \%\end{array}$ \\
\hline Rearfoot & Sx & $D x$ \\
\hline $\begin{array}{l}\text { Surface }(\mathrm{cm},) \\
\text { Load }(\mathrm{Kg}) \\
\text { Weight ratio <R F> }\end{array}$ & $\begin{array}{l}61.00 \\
51.2 \\
79.5 \%\end{array}$ & $\begin{array}{l}45.25 \\
35.3 \\
99.2 \%\end{array}$ \\
\hline Total & $S x$ & $D x$ \\
\hline $\begin{array}{l}\text { Surface }(\mathrm{cm},) \\
\text { Load }(\mathrm{kg})\end{array}$ & $\begin{array}{l}82.75 \\
64.3 \% \\
47.6 \\
64.4 \%\end{array}$ & $\begin{array}{l}46.00 \\
35.7 \% \\
26.4 \\
35.6 \%\end{array}$ \\
\hline $\begin{array}{l}\text { Foot angle (9) } \\
\text { Foot Angle Axis ( } 9\end{array}$ & $\begin{array}{l}5.1 \\
18.3\end{array}$ & $\begin{array}{l}7.0 \\
33.8\end{array}$ \\
\hline
\end{tabular}

Figure 7. Subject 1: $\mathrm{C}=$ center of pressure $(\mathrm{COP})$; $\mathrm{L}$ and $\mathrm{R}=$ center of each foot (left \& right); $\mathrm{M}=$ point of maximum pressure. 


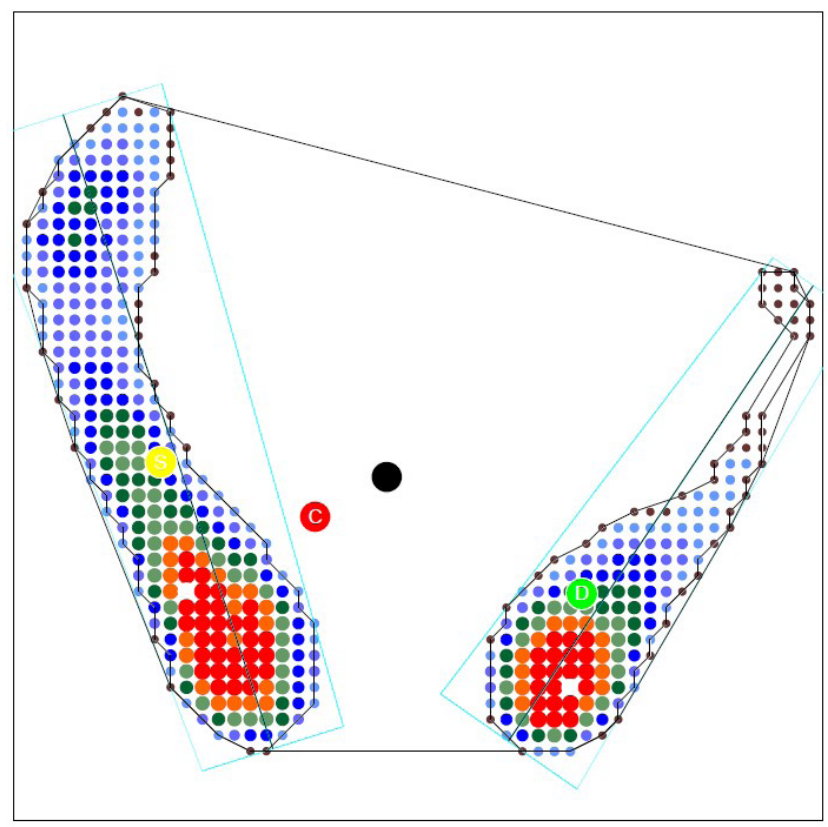

- The $\mathrm{COP}=\mathrm{Center}$ of Pressure - shown with the red bullet with the letter "C" - corresponds to the body's gravity center projection on the ground;

- The $\mathrm{COF}=$ Center of each Foot (shown with yellow and green bullets);

- Pressure is coded using colors - red for higher values and light blue for lower ones; the points of medium pressure are represented with green/orange shades.

Figure 8. Subject 1: Results and legend.

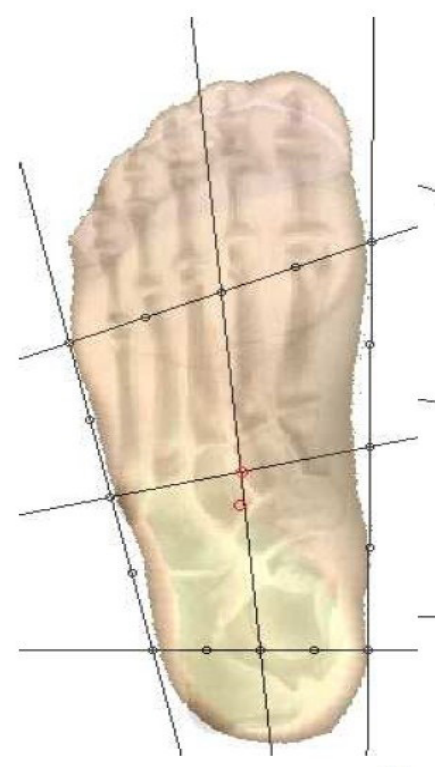

Foot Length Metatarsal Width Midfoot Length

Heel Width

Heel Length
Heel Perimeter

Heel Perimete

Shoe \#:

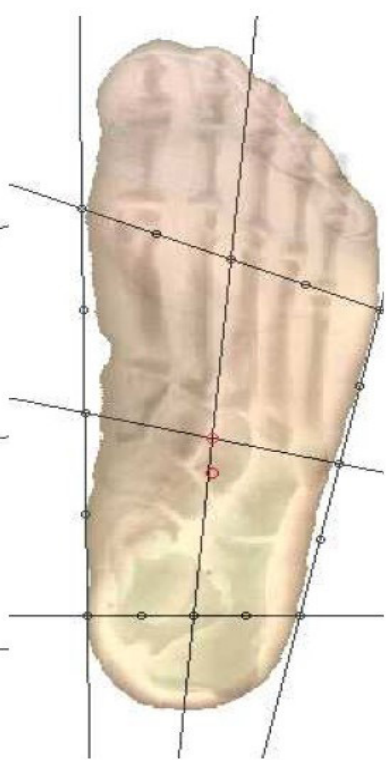

LF
23.41
9.6
12.5
6.36
6.47
10.08
6.18
6.5

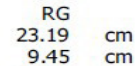

$9.45 \mathrm{~cm}$

$12.38 \mathrm{~cm}$
$6.25 \mathrm{~cm}$

$6.25 \mathrm{~cm}$
$6.36 \mathrm{~cm}$

$9.9 \mathrm{~cm}$

$3.55 \mathrm{~cm}$
6

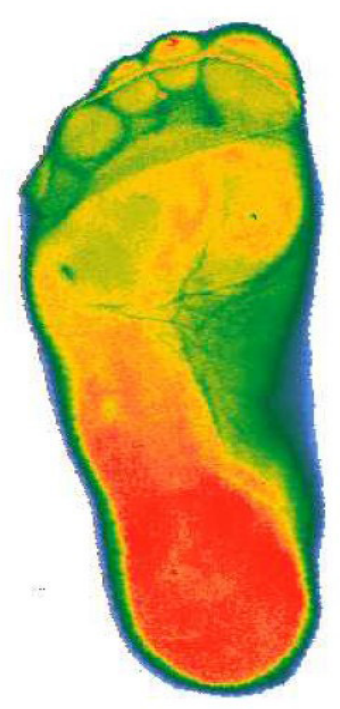

Foot Angle

Divergence Angle

Tarsal Epicenter

Centroid (to end rearfoot)

Subtalar Joint Med angle

Subtalar Joint Lat angle

Left Foot

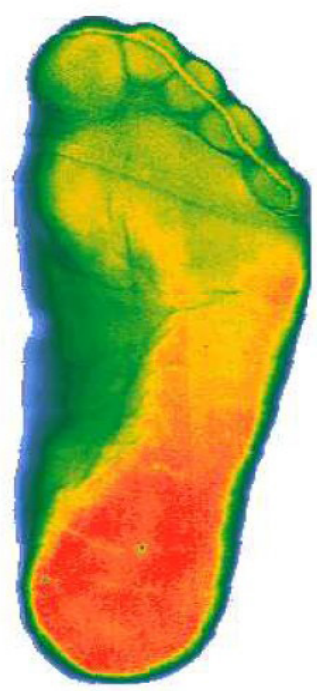

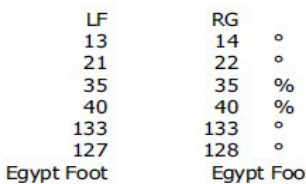

Figure 9. Subject 2: Feet dimensions and characteristics. 


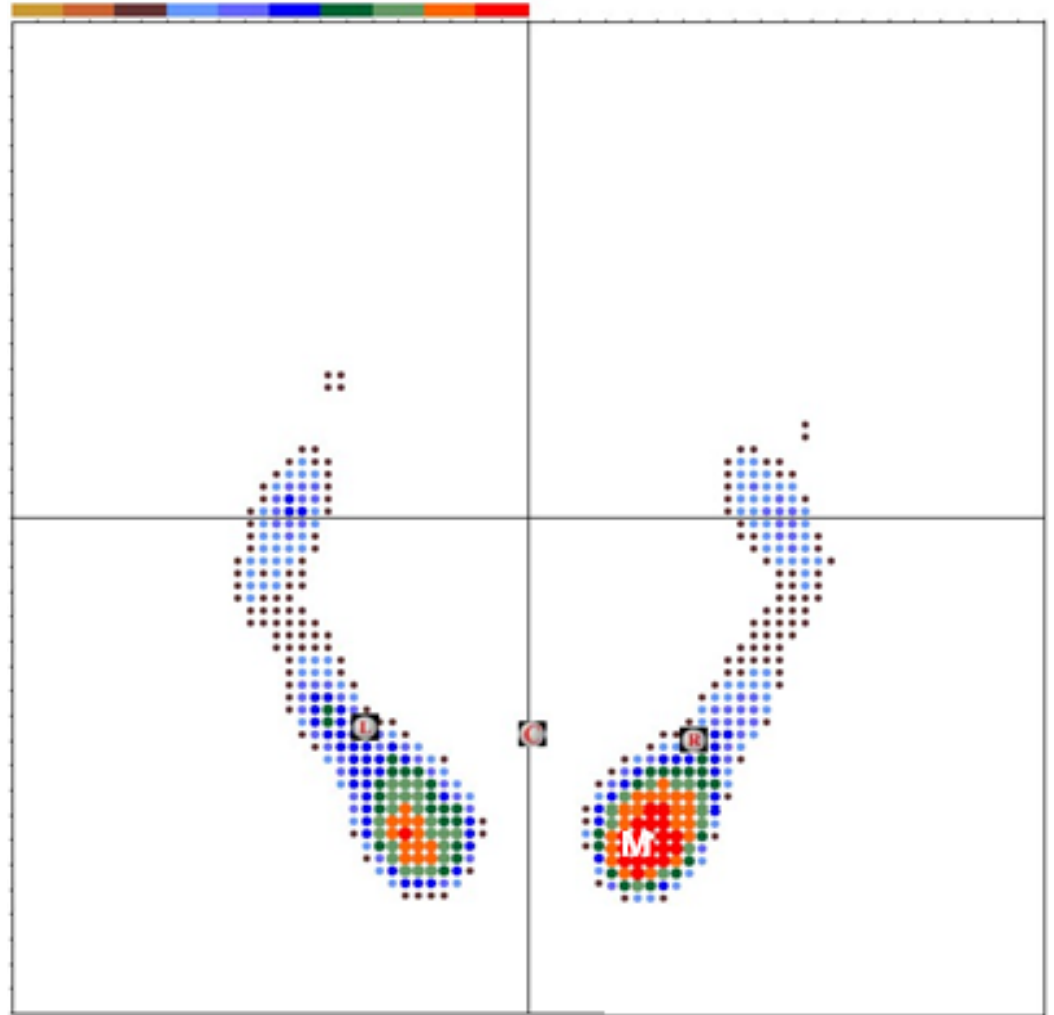

\begin{tabular}{|c|c|c|}
\hline $\begin{array}{l}\text { Surface }(\mathrm{cm},) \\
\text { P.Max }(\mathrm{g} / \mathrm{cm},) \\
\text { P.Avg }(\mathrm{g} / \mathrm{cm}) \\
\text { Feet angle }(g) \\
\text { CoF }\langle\mathrm{L}-\mathrm{R}\rangle \text { angle }\left({ }^{\circ}\right)\end{array}$ & & $\begin{array}{l}127.75 \\
839.7 \\
383.6 \\
42.1 \\
-2.3\end{array}$ \\
\hline Forefoot & Sx & $D x$ \\
\hline $\begin{array}{l}\text { Surface }(\mathrm{cm},) \\
\text { Load }(\mathrm{Kg}) \\
\text { Weight ratio <R F> }\end{array}$ & $\begin{array}{l}8.50 \\
4.9 \\
9.9 \%\end{array}$ & $\begin{array}{l}8.75 \\
4.8 \\
9.4 \%\end{array}$ \\
\hline Rearfoot & $S x$ & $\mathrm{Dx}$ \\
\hline $\begin{array}{l}\text { Surface }\left(\mathrm{cm}_{\mathrm{s}}\right) \\
\text { Load }(\mathrm{Kg}) \\
\text { Weight ratio <R F> }\end{array}$ & $\begin{array}{l}56.00 \\
44.3 \\
90.1 \%\end{array}$ & $\begin{array}{l}54.50 \\
46.0 \\
90.6 \%\end{array}$ \\
\hline Total & Sx & $\mathrm{Dx}$ \\
\hline Surface $\left(\mathrm{cm}_{\mathrm{S}}\right)$ & $\begin{array}{l}64.50 \\
50.5 \% \\
24.1 \\
49.2 \%\end{array}$ & $\begin{array}{l}63.25 \\
49.5 \% \\
24.9 \\
50.8 \%\end{array}$ \\
\hline $\begin{array}{l}\text { Foot angle (") } \\
\text { Foot Angle Axis (9) }\end{array}$ & $\begin{array}{l}6.9 \\
20.5\end{array}$ & $\begin{array}{l}0.3 \\
21.6\end{array}$ \\
\hline
\end{tabular}

Figure 10. Subject 2: $\mathrm{C}=$ center of pressure $(\mathrm{COP}) ; \mathrm{L}$ and $\mathrm{R}=$ center of each foot (left \& right); $\mathrm{M}=$ point of maximum pressure.

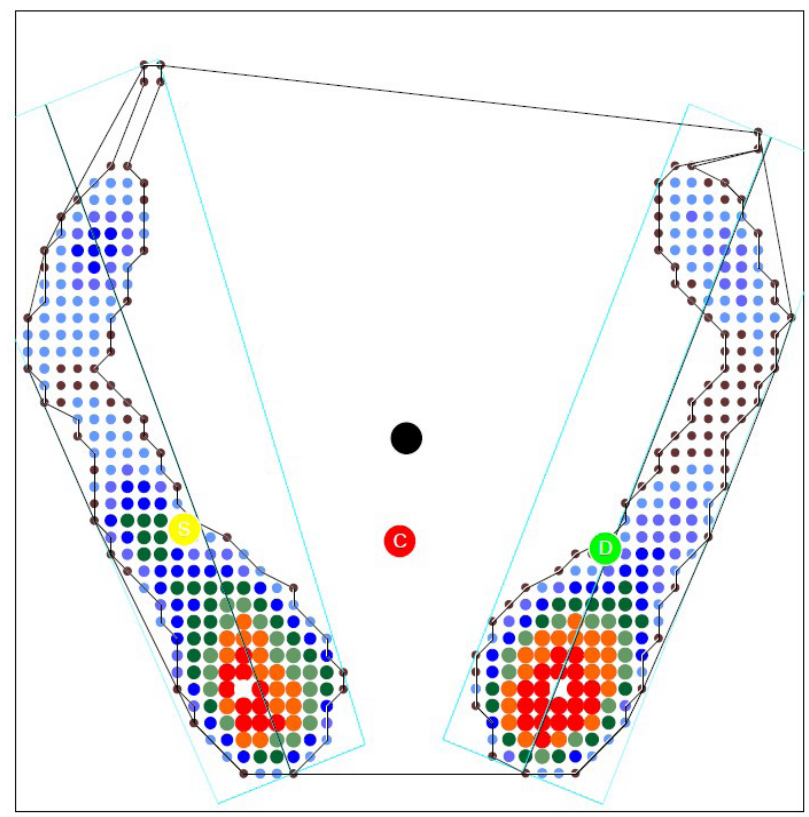

- The $\mathrm{COP}=$ Center of Pressure - shown with the red bullet with the letter "C" - corresponds to the body's gravity center projection on the ground;

- The $\mathrm{COF}=\mathrm{Center}$ of each Foot (shown with yellow and green bullets);

- $\quad$ Pressure is coded using colors - red for higher values and light blue for lower ones; the points of medium pressure are represented with green/orange shades;

Figure 11. Subject 2: Results and legend. 

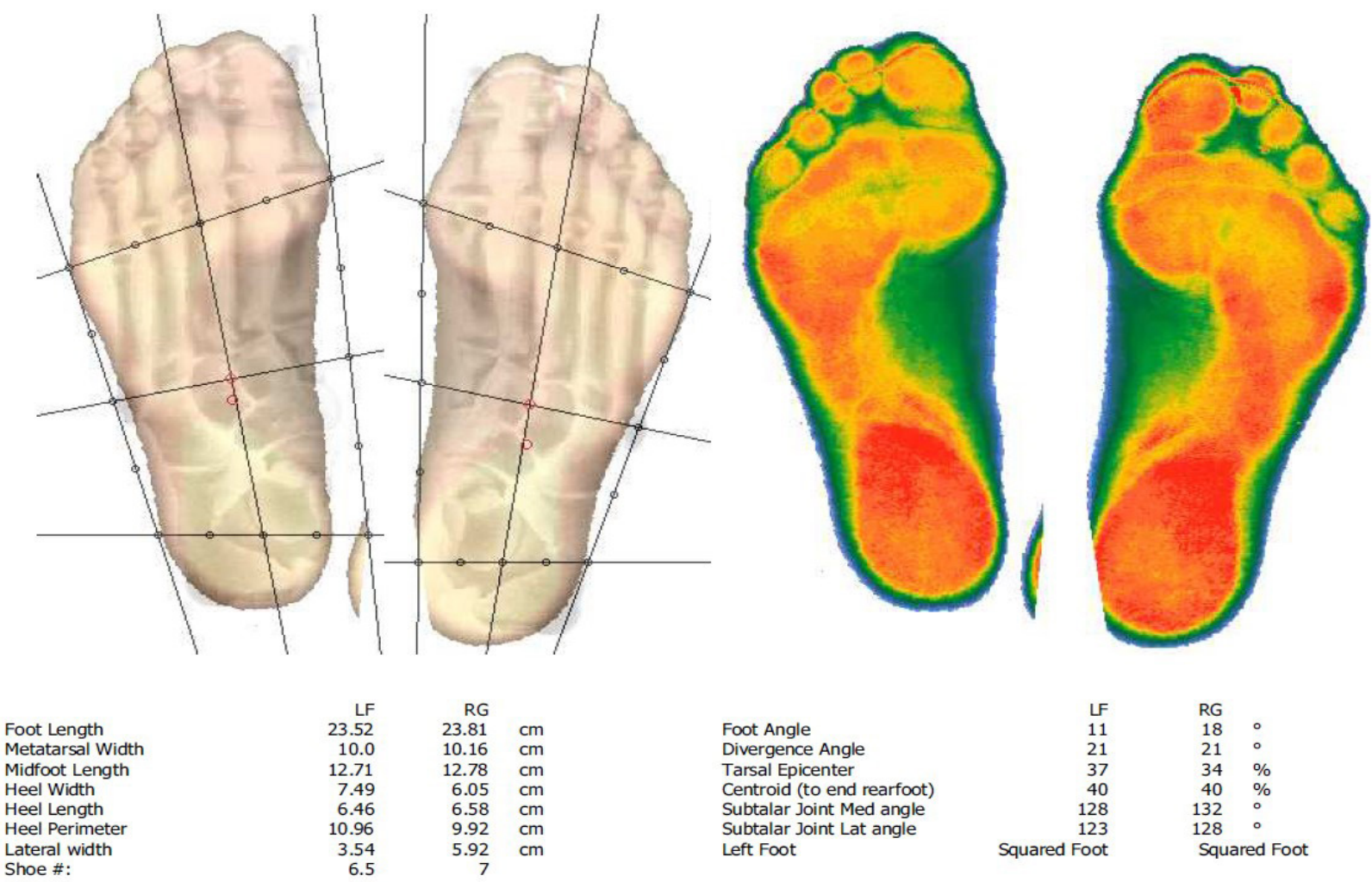

$\begin{array}{rrr}\text { LF } & \text { RG } & \\ 23.52 & 23.81 & \mathrm{~cm} \\ 10.0 & 10.16 & \mathrm{~cm} \\ 12.71 & 12.78 & \mathrm{~cm} \\ 7.49 & 6.05 & \mathrm{~cm} \\ 6.46 & 6.58 & \mathrm{~cm} \\ 10.96 & 9.92 & \mathrm{~cm} \\ 3.54 & 5.92 & \mathrm{~cm} \\ 6.5 & 7 & \end{array}$

Foot Angle

Divergence Angle

Tarsal Epicenter

Centroid (to end rearfoot)

Subtalar Joint Med angle

Subtalar Joint Lat angle

Left Foot

\begin{tabular}{|c|c|c|}
\hline LF & RG & \\
\hline 11 & 18 & 。 \\
\hline 21 & 21 & 。 \\
\hline 37 & 34 & $\%$ \\
\hline 40 & 40 & $\%$ \\
\hline 128 & 132 & $\circ$ \\
\hline 123 & 128 & $\circ$ \\
\hline Squared Foot & Squ & red Foc \\
\hline
\end{tabular}

Figure 12. Subject 3: Feet dimensions and characteristics.

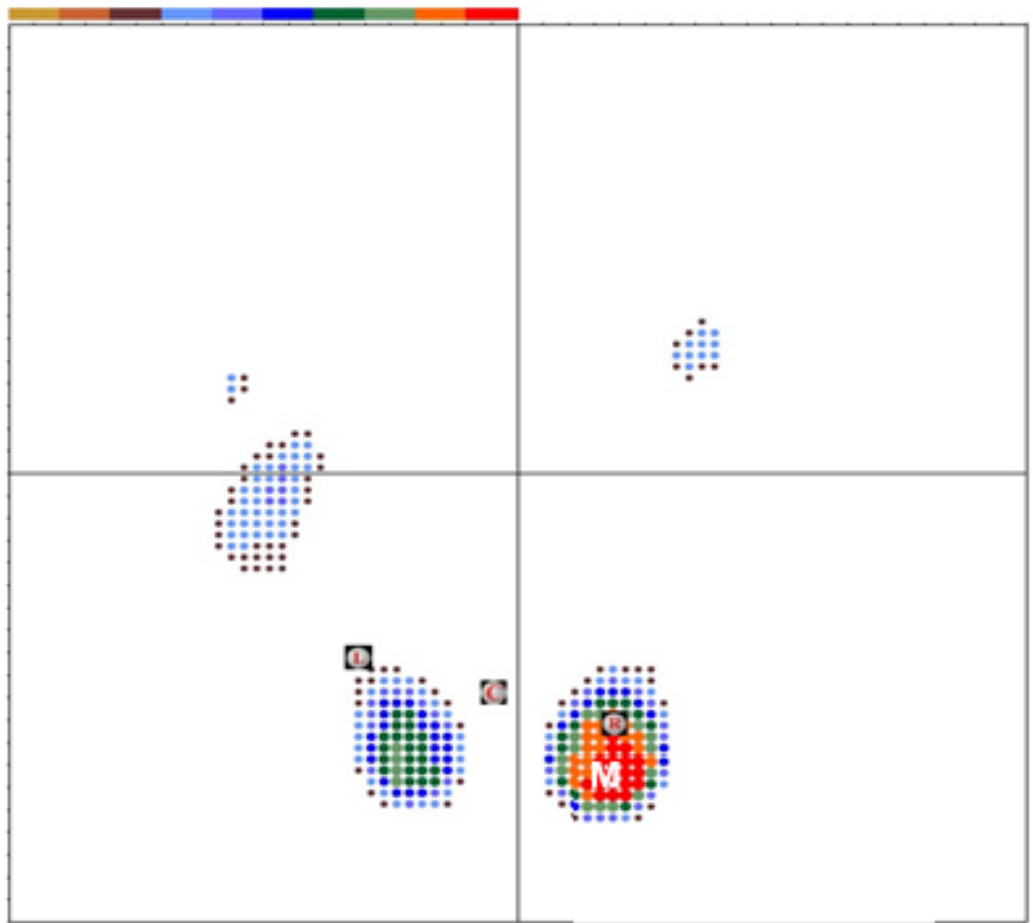

Surface $(\mathrm{cm})$

P.Max $(\mathrm{g} / \mathrm{cm})$

P. Avg $(g / \mathrm{cm})$

Feet angle (')

CoF $\angle \mathrm{L}-\mathrm{R}>$ angle ( $) \quad-16.2$

675.2

37.9

Forefoot Sx Dx

Surface $(\mathrm{cm}) \quad 6.00 \quad$,

Load $(\mathrm{Kg}) \quad 4.7 \quad 3.5$

Weight ratio <R F> $\quad 10.0 \% \quad 6.6 \%$

Rearfoot Sx Dx

Surface (cm) $\quad 38.50 \quad 29.75$

Load $(\mathrm{Kg}) \quad 42.4 \quad 49.5$

$\begin{array}{lll}\text { Weight ratio <R F> } \quad 90.0 \% & 93.4 \%\end{array}$

Total Sx Dx

Surface $(\mathrm{cm})$

Load $(\mathrm{kg})$

$44.50 \quad 34.00$

$25.0 \quad 28.0$

$47.1 \% \quad 52.9 \%$

Foot angle $(9$

$\begin{array}{ll}3.9 & 10.2 \\ 26.6 & 11.3\end{array}$

Figure 13. Subject 3: $C=$ center of pressure $(\mathrm{COP})$; $\mathrm{L}$ and $\mathrm{R}=$ center of each foot (left \& right); $\mathrm{M}=$ point of maximum pressure. 


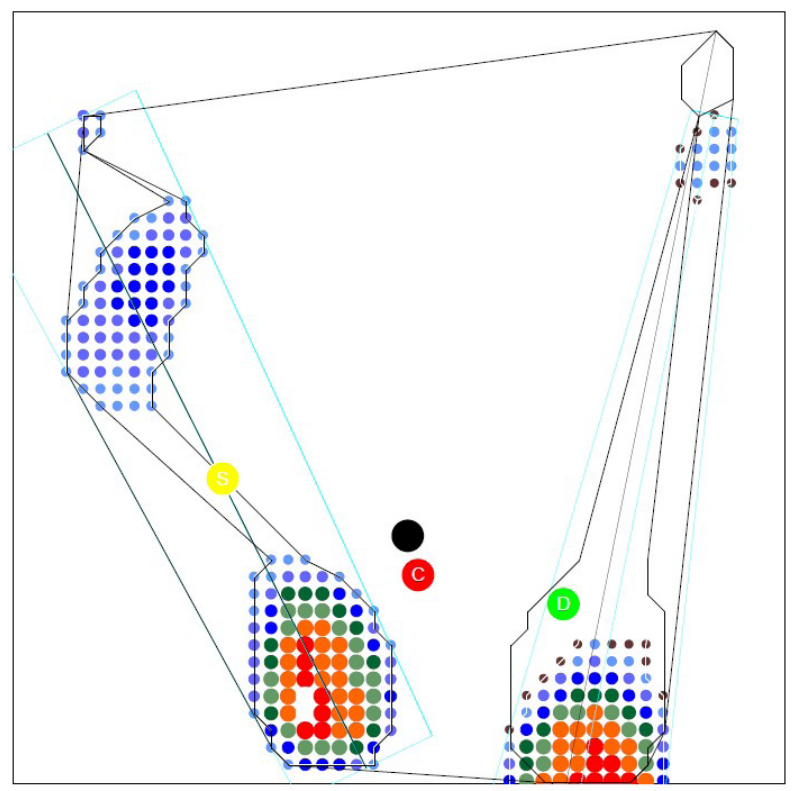

Figure 14. Subject 3: Results and legend.

The results for each of the 3 subjects are represented in figures 6 through 14, including the dimensions and characteristics of the plantar surfaces.

In subject 1 , the COP is visualized more on the left side, indicating an excessive mono-lateral load and it is also backward, indicating more rearfoot support. The COF shows a misalignment in relation to COP, indicating a rotated attitude: the left one is forwarded, the right one is backwarded. The point of maximum pressure is detected in the right rearfoot area. Feet surfaces have different distribution areas, more on the left. As far as the forefoot area is concerned, an excessive surface difference is highlighted, more on the left. The same applies for the rearfoot surface distribution. The maximum points of pressure are detected on both rear-feet, more on the left, pointing out a mono-lateral load distribution (Figure 6, 7 and 8).

In subject 2, the COP is visualized centrally and backward, indicating more rearfoot support. The COFs show a misalignment in relation to COP, a pathological condition that implies a rotated attitude, the left one being forwarded while the right one is backwarded. The maximum point of pressure is detected in the right rearfoot area. The load distribution on each leg evidences a good body weight distribution between the left and right legs. The load distribution between forefoot and rearfoot is within the physiological values on both feet. Feet surfaces have a similar area of distribution. The maximum points of pressure are detected on both rear-feet, more on the right foot, indicating a mono-lateral load - excessive load areas.
- The $\mathrm{COP}=\mathrm{Center}$ of Pressure - shown with the red bullet with the letter "C" - corresponds to the body's gravity center projection on the ground;

- The $\mathrm{COF}=\mathrm{Center}$ of each Foot (shown with yellow and green bullets);

- $\quad$ Pressure is coded using colors - red for higher values and light blue for lower ones; the points of medium pressure are represented with green/orange shades;
The points of medium points of pressure are both in rearfeet area, more on the left (Figure 9, 10 and 11).

In subject 3, the COP is visualized on the right, indicating an excessive mono-lateral distribution of load, it is also backwarded showing more rearfoot support. The COFs show a misalignment in relation to COP, again implying a rotated attitude: the left one is forwarded, the right one is backwarded. The maximum point of pressure is detected in the right rearfoot area. The load distribution on each leg evidences a good body weight distribution between left and right legs. The load distribution between forefoot and rearfoot on both legs is within the physiological values. Feet surfaces have different area distribution, more on the left. Between the forefeet an excessive surface difference is highlighted, more on the left. Between the rear-feet an excessive surface difference is highlighted, more on the right. The maximum points of pressure are detected on both rear-feet, more on the right, pointing out mono-lateral load area (Figure 12, 13 and 14).

\section{Discussion}

MSDs come inherently with the job in this profession, with postural errors exacerbating existing MSDs or, more importantly, becoming etiological factors for completely new ones. According to one study, more than $50 \%$ of dentists over the age of 45 are practicing in erroneous positions. Such stances can lead to neck, shoulder and back pain, the latter being reported as a major cause of work absences and thus economic and quality of life losses. Musculoskeletal issues can however be avoided, 
at least partially, by modifying the working routine and by maintaining the correct position [6,7].

The correct working position, according to Anghel et al. (2007), is a neutral and symmetrical posture, in which the practicing dentist is seated with all horizontal axes parallel, the legs being slightly split apart, the torso perpendicular to the floor, arms close to the body, forearms horizontal, head flexed by $20-25^{\circ}$ and the soles of the feet completely on the floor [6] (Figure 2).

Even though baropodometry is a trialed and tested method of evaluating MSDs [9], its use in occupational health is limited, with no large study or trial being published about its use in the specific field of dental healthcare professionals injuries and diseases [11]. Comparing our results to other published studies is difficult because of differences in calibration and reliability of hardware and standardization of the technique. Analysis through baropodometry requires further studies with a standard technique and universally calibrated equipment (hardware and software).

The limits of this study are linked to the reduced number of subjects included, therefore, we conclude that further studies with a greater number of subjects are required, especially ones using the biopostural analysis software and equipment. Another aspect is related to clinician BMI, as no obese subjects were included in the study and body mass; as studies have shown, BMI is strongly correlated with MSDs (especially LBP) $[12,13,14,15]$. We must also take into account the fact that the 3 subjects included all had a right dominant foot, determined via self-reporting. We consider the lack of left foot dominant subjects another limit of this study [4].

We hope this study can become a starting point for others and a valid tribute for the usefulness of baropodometric analysis in MSDs caused by incorrect posture.

\section{Conclusion}

Baropodometric analysis of test subjects has shown the following alterations:

1. The body's center of gravity in static orthostatism was shifted to one side in 2 of the 3 subjects.

2 . The body's center of gravity was shifted towards the rearfeet in all 3 subjects.

3 . The center of each foot was misaligned in all 3 subjects, indicating a rotated stance, probably as a consequence of trying to maintain good balance, a good field of view and workspace in prolonged orthostatism.

4. The point of maximum pressure was located in the right rearfoot area in all 3 subjects.

5. All subjects exhibited areas of excessive plantar weight distribution

\section{References}

1. Morbeck ME. Primate morphophysiology, locomotor analyses and human bipedalism. Int J Primatol. 1986;7:423425.

2. Rodman PS, McHenry HM. Bioenergetics and the origin of hominid bipedalism. Am J Phys Anthropol. 1980;52:103106.

3. Hoy D, March L, Brooks P, Blyth F, Woolf A, Bain C, et al. The global burden of low back pain: estimates from the Global Burden of Disease 2010 study. Ann Rheum Dis. 2014;73:968-974.

4. van Melick N, Meddeler BM, Hoogeboom TJ, Nijhuis-van der Sanden MWG, van Cingel REH. How to determine leg dominance: The agreement between self-reported and observed performance in healthy adults. PLoS One. 2017; 12:e0189876.

5. Cosoroaba MR, Cirin L, Anghel MD, Talpos-Niculescu CI, Argesanu V, Farkas AZ, et al. The use of thermal imaging in evaluating musculoskeletal disorders in dentists. J Med Life. 2019;12:247-252.

6. Anghel M, Argesanu V, Talpos-Niculescu C, Lungeanu D. Musculoskeletal disorders (MSDs) consequence of prolonged static posture. Journal of Experimental Medical \& Surgical Research. 2007;4:167-172.

7. Fish DR, Morris-Allen DM. Musculoskeletal disorders in dentists. N Y State Dent J. 1998;64:44-48.

8. Delleman NJ, Dul J. International standards on working postures and movements ISO 11226 and EN 1005-4. Ergonomics. 2007;50:1809-1819.

9. Baumfeld D, Baumfeld T, da Rocha RL, Macedo B, Raduan F, Zambelli R, et al. Reliability of Baropodometry on the Evaluation of Plantar Load Distribution: A Transversal Study. Biomed Res Int. 2017;2017:5925137.

10. Kenny VV, Nolivos V, Alegría F. Preventive and curative importance of the baropodometric analysis for ergonomics and occupational health. Work. 2012;41 Suppl 1:1896-1899.

11. Rosário JL. A review of the utilization of baropodometry in postural assessment. J Bodyw Mov Ther. 2014;18:215-219.

12. Shiri R, Karppinen J, Leino-Arjas P, Solovieva S, ViikariJuntura E. The association between obesity and low back pain: a meta-analysis. Am J Epidemiol. 2010;171:135-154.

13. Aghahi RH, Darabi R, Hashemipour MA. Neck, back, and shoulder pains and ergonomic factors among dental students. J Educ Health Promot. 2018;7:40.

14. Son SM. Influence of Obesity on Postural Stability in Young Adults. Osong Public Health Res Perspect. 2016;7:378-381.

15. Song J, Kane R, Tango DN, Veur SS, Furmato J, Komaroff $\mathrm{E}$, et al. Effects of weight loss on foot structure and function in obese adults: a pilot randomized controlled trial. Gait Posture. 2015;41:86-92. 